\title{
Analysis of Faculty Perceptions toward Blended Learning Adoption at Higher Education Institutes in Oman
}

\author{
Virendra Gawande, PhD \\ Sur College of Applied Sciences, \\ (Ministry of Higher Education), Oman
}

\begin{abstract}
This study is mainly intended to identify the factors affecting blended learning adoption, and to find out whether the teaching process is predictive in its adoption at HEIs in Oman. The study adopted quantitative approach that aimed to examine the effect of teaching styles on blended learning adoption. The findings revealed that teaching styles, significantly mediated the relationship of User Acceptance of Technology (UAT) and Blended Learning adoption. Blended learning in the theoretical framework may improve the interaction in learning environment and support effective learning, through greater flexibility. This research is an extension to the study conducted erstwhile on evaluating the perceptions of "Students" towards blended learning adoption at HEIs in Oman [4].
\end{abstract}

\section{Keywords}

eLearning, Blended Learning, Teaching Styles, User Acceptance of Technology, Behavioural Intention.

\section{INTRODUCTION}

With the rapid development of internet technologies, distance education has evolved; in particular the web based educational tools and compressed videos. This form of flexible mode of course delivery has given rise to a new concept called online learning, also referred to as eLearning [7]. Harasim [6] refers to online learning as a combination of distance education and traditional face-to-face education using computer mediated instruction. Most of the education providers including HEI in Oman, have implemented flexible learning through eLearning technologies. Richard [9] explained the categories of flexible learning environment as follows:

- None or trivial online presence: It is based on traditional classroom environment with usage of electronic tools.

- Web supplemented: Students use course documents provided by lecturers, communicate by emails and refer to external links for additional course information.

- Web dependent: Students participate in key course activities through online discussion, discussion board while attending classroom.

- Mixed mode: Students need to participate in online activities as course requirement as well as attending class room sessions. Some part of classroom sessions can be replaced. This method has been implemented at HEI in Oman.

- Fully online: Students need not to attend classroom lectures.

CAS, in Oman adopted a mixed mode of teaching, where "students are required to participate in online activities, e.g. online discussions, assessments, online project/ collaborative work, as part of the course work, which replace part of the face-to-face teaching/ learning. Significant campus attendance remains" [9].

In Oman, College of Applied Sciences (CAS) initiated an attempt towards the Blended Learning in 2007. The aim was to enhance teaching and learning and also improve the access of the information resources.

Blended learning provides the online courses that require students to attend classroom lectures and also participate online. At CAS, the online courses are increasing significantly. One of the key objectives of CAS includes "Leadership in technical and further education", by developing multimedia tools, and the rapid growth in online and distance education facilities with the flexibility of time and space.

\section{STATEMENT OF THE PROBLEM}

Blended learning is more relevant to Oman, as the youth (under the age of 25 years) constitute its major population and there is no other way to take education to a better scale without the intervention of technology.

Oman adopted ICT later than many developed economies, confronting challenges of providing sufficient infrastructure for its widespread population. The adoption of technologies in is a challenge for the government of Oman, as the younger members of society embrace social networking, and conservative sections of the community require encouragement to utilize these services.

The other challenges, includes increasing student numbers, gender segregation, lack of faculty members, and inadequacy of learning resources. Despite the challenges, the adoption of ICT in education is fundamental objective to the government of Oman, for spreading computer literacy.

Most HEI in Oman offers undergraduate and postgraduate degrees, and accept all Omani students. The establishment of new private universities and colleges across the country therefore enhances higher education access to majority of Omani citizens.

However, in a traditionalist and rich society like Oman, higher education offers several unique circumstances that suggest that, curriculum delivery using blended learning is a rational choice. These are increase in student numbers, coupled with an inadequate number of qualified instructors which has led to a situation where the traditional system is unable to respond, and thus, an initiative leading towards blended learning is promising.

Government of Oman has taken cognizance of the institutional support required for resources in eLearning and formulated the national mission on education through ICT. Thus, the grounds for conducting this study are to support the government policies on blended learning, and the Ministry of 
Higher Education and CAS administration and faculty in delivering the government's objectives.

To the best of researcher's knowledge, there were no significant studies on technology acceptance of blended learning that includes factors related to students and teachers within the same model. Thus this research study may be very significant.

\section{RESEARCH OBJECTIVES}

The purpose of this study was to identify the factors affecting the adoption of blended learning and to study whether teaching and learning process is predictive in its adoption, and develop a blended learning model to be adopted at CAS in Oman. The specific research objectives were as follows:

- To examine the factors of User Acceptance of Technology, affecting the Behavioural Intention (Blended Learning) at CAS.

- To examine the impact of Demographic variables, Teaching styles on Behavioural Intention (Blended Learning) at CAS.

- To what extent the Teaching style is considered as mediators affecting the relationship between User Acceptance of Technology and Behavioural Intention (Blended Learning) at CAS.

\section{RESEARCH QUESTIONS}

The main research questions was, How do teaching and learning process affects the blended learning adoption at CAS in Oman? However, there were secondary research questions that guided this study.

1. What are the factors of User Acceptance of Technology and how it affects the Behavioural Intention (Blended Learning) at CAS?

2. What is the impact of Demographic variables and Teaching styles on Behavioural Intention (Blended Learning) at CAS?

3. To what extent the Teaching styles is considered as mediators affecting the relationship between User Acceptance of Technology and Behavioural Intention (Blended Learning) at CAS?

\section{RESEARCH HYPOTHESES}

The following hypotheses were considered for this study:

H1: Performance Expectancy of teachers has significant influence on Blended Learning adoption.

H2: Effort Expectancy of teachers has significant influence on Blended Learning adoption.

H3: Social Influence of teachers has significant influence on Blended Learning adoption.

H4: Facilitating Conditions for teachers has significant influence on Blended Learning adoption.

H5: The relationship between User Acceptance of Technology and the Behavioural Intention (Blended Learning) is mediated by the Teaching style.

H6: The relationship between User Acceptance of Technology and the Behavioural Intention (Blended Learning) is affected by the Demographic variables of teachers.

\subsection{Theoretical background}

There are several models have been identified adoption of technologies and to predict usage and behaviour. In order to predict the individual adoption of technologies, models like Theory of Reasoned Action (TRA), Technology Acceptance Model (TAM), Technology of Acceptance (TAM) [10], Theory of Planned Behaviour (TPB) and Unified Theory of Acceptance and Use of Technology (UTAUT) [10] had been widely used and validated tested by several researchers. The present study utilized UTAUT model which was proposed by Venkatesh [10], and ELAM proposed by Khan and Iyer (2009) for specifically eLearning acceptance [2]. In the present study context, researcher developed the model based on the ELAM and UTAUT. This is because, the existing ELAM was developed for eLearning and secondly, actual usage was removed as implementation of blended learning in Oman is at earlier stage. Further, the model also included demographic variables as a moderator to predict the adoption behaviour. The model consisted of four constructs namely effort expectancy, performance expectancy, facilitating condition and social influence which are direct determinants of behavioural intention. Demographic factors such as gender, age and computer experience was used as moderating variable while learning style of students was used as mediating variable. Figure 1, depicts the adjusted ELAM model adopted for blended learning at CAS.

\subsection{Teaching Style Inventory}

Scores teaching style on separate scales, for each of the five predominant teaching styles viz. Delegator, Facilitator, Personal Model (or Demonstrator), Formal Authority, and Expert [5].

- Expert: Possesses knowledge and expertise that students need. Strives to maintain status as an expert among students by displaying detailed knowledge and by challenging students to enhance their competence. Concerned with transmitting information and insuring that students are well prepared.

- Formal Authority: Possesses status among students because of knowledge and role as a faculty member. Concerned with providing positive and negative feedback, establishing learning goals, expectations, and rules of conduct for students. Concerned with the correct, acceptable, and standard ways to do things and with providing students with the structure they need to learn.

- Personal Model: Believes in "teaching by personal example" and establishes a prototype for how to think and behave. Oversees, guides, and directs by showing how to do things, and encouraging students to observe and then to emulate the instructor's approach.

- Facilitator: Emphasizes the personal nature of teacher-student interactions. Guides and directs students by asking questions, exploring options, suggesting alternatives, and encouraging them to develop criteria to make informed choices. Overall goal is to develop in students the capacity for independent action, initiative, and responsibility. Works with students on projects in a consultative fashion and tries to provide as much support and encouragement as possible. 
- Delegator: Concerned with developing students' capacity to function in an autonomous fashion. Students work independently on projects or as part of autonomous teams. The teacher is available at the request of students as a resource person.

\section{RESEARCH METHODOLOGY}

The present empirical research was based on data collected from three academic departments of CAS i.e., Department of Information Technology, Department of Communication and Department of General Requirements. The participants were chosen using convenience sampling method, since this technique helps to select the participants who can best answer the research questions [8], rather than choosing the generalized population. The questionnaire was sent to 40 faculty members, out of which only 30 participants responded with a response rate of $75 \%$. The data collection was done during the year 2012-2013.

\subsection{Research Tools}

The research instrument adopted was structured questionnaire already been validated by previous studies empirically [10] with 39 items to measure the user acceptance [Behavioural intention (3 items), Facilitating conditions ( 9 items), Social influence (5 items), Performance expectancy (14 items), and Effort expectancy (8 items)] and Teaching styles adopted from Riechmann and Grasha [5]. In addition, questionnaire also captured demographic information, age, gender, computer and internet experience. In this study 4 factors that would predict user acceptance were considered as independent variables, teaching style was considered as mediator while behavioural intention as dependent variable. Further, demographic and computer usage was considered as a moderator. The questionnaire employed 5-point Likert Scale (Strongly disagree; Disagree; Neutral; Agree and Strongly agree) to grade the responses. The survey instrument was developed based on the previous UTAUT and other models. Initially, pilot study was conducted to test the reliability of questionnaire with academic experts. This helps to assess whether there are any ambiguities present in the questionnaire. Based on the suggestions, minor changes were made in the survey instrument. The items in the questionnaire were developed by relying on the research objectives [1].

\section{DATA ANALYSIS}

Collected data from the study sample were statistically computed using SPSS software (IBM Corp. Released 2012, version 21.0). Descriptive statistics was used to compute the average mean of the scores and standard deviations for all the employed variables. The reliability and validity of the questionnaire was tested using Cronbach's alpha. Factor analysis was used to identify dimensions and the underlying dimensions of user acceptance technology. To examine the impact of user acceptance on adoption of blended learning technology, multiple regression analysis was applied. To analyse the mediation, Sobel test was applied. The conditions for mediation tests was examined through four steps test such as: the total effect of $\mathrm{X}$ on $\mathrm{Y}$, the effect of $\mathrm{X}$ on $\mathrm{M}$, the effect of $\mathrm{M}$ on $\mathrm{Y}$ and the effect of $\mathrm{X}$ on $\mathrm{Y}$ controlled for $\mathrm{M}$, and these four steps needed to be significant and satisfied [3]. In addition, to examine the role of covariant such as demographic factors and on the relationship between user acceptance and adoption of technology, multivariate analysis of covariance (MANCOVA) was applied. All measurement items were standardized and missing values were replaced by sample means to examine validity, reliability, and statistical power and the existing relationships. The impacts of each factor were represented by the path coefficients and corresponding levels of significance. $\mathrm{P}$ value $<0.05$ was considered significant in the study.

\section{RESULTS}

The demographic characteristics of participants $(n=30)$ who responded to the study were as follows:

From the present findings it was observed that the respondents were equally from the departments $(33.3 \%)$ and age group with $20-30$ and $>30$ years $(50.0 \%)$, male and female $(50.0 \%)$ and with experience $0-5$ years $(50.0 \%)$. Thus it was clear that the study had generated responses from varied range of respondents adequately representing the diversity of the total population of employees in the organization.

The findings of the present study in relation to teaching style namely Expert, Formal Authority, Personal Model, Facilitator, and Delegator were identified as the major key factors.

Reliability and validity tests were conducted on constructs with multivariate measures. Cronbach's reliability was applied to measure the internal consistency of these multivariate scales. The reliability of the factors of theoretical model ranges from $0.548-0.913$. Thus, testing the instrument is highly applicable to present sample in the study.

The results (Table 1) show that the Cronbach's alpha for most of the dimensions were greater than 0.7 , which indicates higher level of reliability for the survey instrument in the study [12]. Further the reliability of Teaching style had five factors as; Expert, Formal Authority, Personal Model, Facilitator, and Delegator and their Cronbach's alpha ranged from $0.692-0.911$.

Table 2 presents the regression analysis and shows a significant association between Performance expectancy $(\beta=0.836, \mathrm{t}=4.847, \mathrm{p}<0.001)$, Effort expectancy $(\beta=0.933$, $\mathrm{t}=4.370, \mathrm{p}<0.001)$ and Social influence $(\beta=0.535, \mathrm{t}=2.541$, $\mathrm{p}<0.001)$ significantly predicted adoption of blended learning at CAS. To examine whether the relationship between user acceptance of technology and blended learning adoption is mediated by teaching styles, the Sobel test was applied. The finding of mediation analysis revealed that teaching style mediate the relationship between Performance expectancy and behavioral intention. 


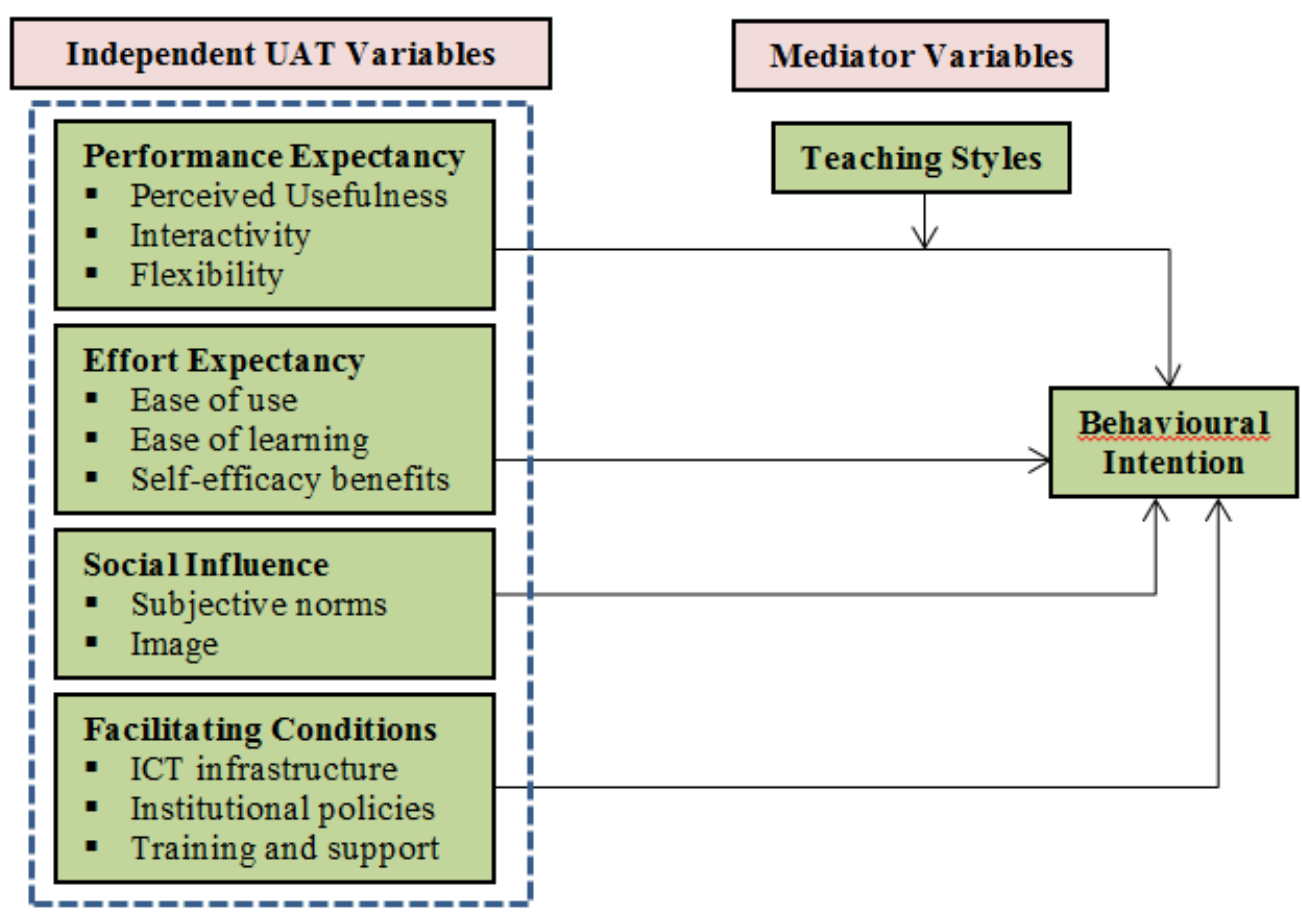

Figure 1: Blended Learning Acceptance Model (BLAM), (A model based on present findings)

\section{CONCLUSION}

The present study has successfully explored the association between behaviour intention (dependent variable) and user acceptance of technology (independent variable) by using teaching style as a mediating variable. This study utilizes both moderator (demographic factors) and mediating variables (teaching style) to identify the impact of user acceptance on behavioural intention (blended learning adoption). In blended learning environment, learning satisfaction is considered as major element and this can be achieved by providing appropriate facility. Student satisfaction was found to be significantly influenced by the factors like perceived usefulness, interactivity and flexibility ease of learning and efficiency of students, subjective norm and image of instructor, institutional policies, leadership of instructor and training and technical support in blended learning adoption. From the findings of the study, it can be concluded that BLAM model is valid, and it has significant effect on blended learning adoption. In learning environment, performance expectancy is considered as important factor for blended learning adoption. Oman is in initial stage in developing adoption of blended learning. This BLAM model might assist to implement blended learning at CAS in Oman by considering Performance Expectancy as an essential factor.

\section{REFERENCES}

[1] Dillman, D. A. 2000. Procedures for conducting government-sponsored establishment surveys: comparisons of the Total design Method (TDM),A Trational Cost-Compensation Model, and Tailored Design, 343-372.

[2] Farida Umrani-Khan and Sridhar iyer. ELAM: A Model for Acceptance and use of e-learning by Teachers and
Students. International conference on e-learning, Toronto, Canada, July, 2009.

[3] Fearson, C. , Starr, S. and McLaughlin, H. 2011. Value of blended learning in university and the workplace: Some experiences of university students. Industrial and Commercial Training, 43 (7), 446-450. http://dx. doi. org/10. 1108/00197851111171872.

[4] Gawande Virendra, 2015. "Development of Blended Learning Model based on the perceptions of Students at Higher Education Institutes in Oman". International Journal of Computer Applications 114(1): 38-45.

[5] Grasha, A. F. (1996). Teaching with style: A practical guide to enhancing learning by understanding teaching and learning styles. Pittsburgh, PA: Alliance Publishers.

[6] Harasim, L. K. (1989). Online education: A new domain. New York: Pergamon.

[7] Ostendorf, V. A. (1997). Teaching and learning at a distance: What it takes to effectively design, deliver, and evaluation programs. San Francisco: Jossey-Bass.

[8] Patton, M. Q. (1990). Qualitative Evaluation and Research Methods. Newbury Park, CA: Sage Publications, Inc.

[9] Richard, G. (2005). E-learning in tertiary education: Where do we stand? Paris: Centre for Education Research and Innovation.

[10] Venkatesh, V., Morris, M. G., Davis, G. B. and Davis, F. D. (2003). User Acceptance of Information Technology: Toward a Unified View. MIS Quarterly, 27(3), 425-478. 


\section{APPENDIX}

Table 1. Reliability of the factors

\begin{tabular}{|c|c|c|}
\hline Factors & No. of items & Cronbach's Alpha \\
\hline \multicolumn{3}{|c|}{ I Performance Expectancy (PE) } \\
\hline Perceived Usefulness & 7 & 0.626 \\
\hline Interactivity & 3 & 0.638 \\
\hline Flexibility & 4 & 0.707 \\
\hline \multicolumn{3}{|c|}{ II Effort Expectancy (EE) } \\
\hline Ease of use & 5 & 0.696 \\
\hline Self-efficiency & 2 & 0.746 \\
\hline \multicolumn{3}{|c|}{ III Social Influence (SI) } \\
\hline Subjective Norm & 2 & 0.913 \\
\hline Image & 3 & 0.872 \\
\hline \multicolumn{3}{|c|}{ IV Facilitating Conditions (FC) } \\
\hline ICT Infrastructure & 3 & 0.804 \\
\hline Institutional Policies & 3 & 0.826 \\
\hline Training and Technical Support & 2 & 0.548 \\
\hline \multicolumn{3}{|c|}{ V Blended Learning (BL) } \\
\hline Behavioural Intention & 3 & 0.738 \\
\hline \multicolumn{3}{|c|}{ VI Teaching Style } \\
\hline Expert & 8 & 0.676 \\
\hline Formal Authority & 8 & 0.803 \\
\hline Personal Model & 8 & 0.911 \\
\hline Facilitator & 8 & 0.826 \\
\hline Delegator & 8 & 0.692 \\
\hline
\end{tabular}

Table 2. Regression analysis

\begin{tabular}{|l|c|c|c|c|}
\hline User acceptance & Beta & t-value & P-value & Accepted/rejected \\
\hline Performance Expectancy & 0.836 & 4.847 & $<0.001$ & Accepted \\
\hline Effort Expectancy & 0.933 & 4.370 & $<0.001$ & Accepted \\
\hline Social Influence & 0.535 & 2.541 & $<0.001$ & Accepted \\
\hline Facilitating Conditions & -0.182 & -1.186 & 0.246 & Partially Rejected \\
\hline
\end{tabular}

